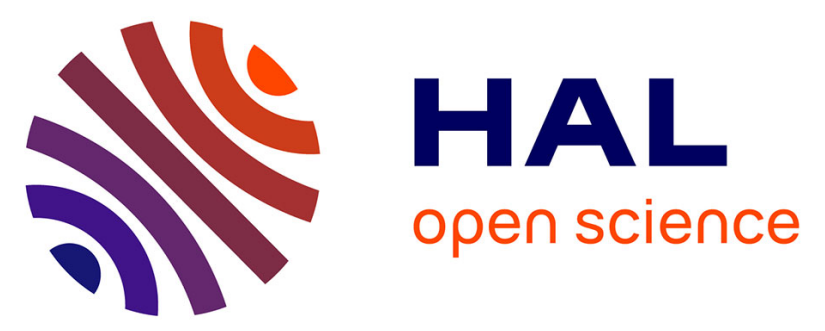

\title{
Ge-rich SiGe based wideband polarization insensitive photonic platform for mid-infrared free-space communications
}

Vladyslav Vakarin, Joan Manel Ramírez, Jacopo Frigerio, Qiankun Liu, Andrea Ballabio, Xavier Le Roux, Carlos Alonso-Ramos, Giovanni Isella, Laurent Vivien, Pavel Cheben, et al.

\section{To cite this version:}

Vladyslav Vakarin, Joan Manel Ramírez, Jacopo Frigerio, Qiankun Liu, Andrea Ballabio, et al.. Ge-rich SiGe based wideband polarization insensitive photonic platform for mid-infrared freespace communications. Silicon Photonics XIV, Feb 2019, San Francisco, United States. pp.32, $10.1117 / 12.2508875$. hal-02362708

\section{HAL Id: hal-02362708 \\ https://hal.science/hal-02362708}

Submitted on 14 Nov 2019

HAL is a multi-disciplinary open access archive for the deposit and dissemination of scientific research documents, whether they are published or not. The documents may come from teaching and research institutions in France or abroad, or from public or private research centers.
L'archive ouverte pluridisciplinaire HAL, est destinée au dépôt et à la diffusion de documents scientifiques de niveau recherche, publiés ou non, émanant des établissements d'enseignement et de recherche français ou étrangers, des laboratoires publics ou privés. 


\title{
Ge-rich SiGe based wideband polarization insensitive photonic platform for mid-infrared free-space communications
}

\author{
Vladyslav Vakarin*a,b,c ${ }^{\text {, Joan Manel Ramírez }}{ }^{\mathrm{a}, \mathrm{d}}$, Jacopo Frigerio ${ }^{\mathrm{e}}$, Qiankun Liu ${ }^{\mathrm{a}}$, Andrea Ballabio, \\ Xavier Le Roux ${ }^{\mathrm{a}}$, Carlos Alonso-Ramos ${ }^{\mathrm{a}}$, Giovanni Isella ${ }^{\mathrm{e}}$, Laurent Vivien ${ }^{\mathrm{a}}$, Pavel Cheben ${ }^{\mathrm{f}}$, \\ Winnie N. Ye ${ }^{b}$, Delphine Marris-Morini ${ }^{\mathrm{a}}$ \\ ${ }^{a}$ Centre de Nanosciences et de Nanotechnologies (C2N), Université Paris Sud, CNRS, Université \\ Paris Saclay, 91120 Palaiseau, France; ${ }^{b}$ Department of Electronics, Carleton University, 1125 \\ Colonel by Dr., Ottawa, ONK1S 5B6, Canada; ${ }^{\mathrm{C} I m e c, ~ K a p e l d r e e f ~ 75, ~} 3001$ Leuven, Belgium; ${ }^{\mathrm{d} I I I-V}$ \\ lab, a joint lab from Nokia Bell Labs, Thales and CEA, 1 avenue Augustin Fresnel, 91767 Palaiseau \\ cedex; ${ }^{\mathrm{C}} \mathrm{L}-\mathrm{NESS}$, Dipartimento di Fisica del Politecnico di Milano, Polo di Como, Via Anzani 42, I \\ 22100 C; ${ }^{\mathrm{f}}$ National Research Council of Canada, Ottawa, ON K1A 0R6, Canada
}

\begin{abstract}
The recent advances in the development of quantum cascade laser with room temperature operation in the mid infrared paved the way for the realization of wideband communication systems. Particularly, two mid-infrared atmosphere transparency windows lying between 3-5 $\mu \mathrm{m}$ and between 8-14 $\mu \mathrm{m}$ exhibit great potential for further implementation of wideband free space communications. Additionally this wide unregulated spectral region shows reduced background noise and low Mie and Rayleigh scattering. Despite the development of a plethora of photonic components in mid infrared such as sources, detectors, passive structures, less efforts have been dedicated to investigate polarization management for information transport. In this work, the potential of Ge-rich SiGe waveguides is exploited to build a polarization insensitive platform in the mid-infrared. The gradual index evolution in SiGe alloys and geometric parameter optimization are used to obtain waveguides with birefringence below $2 \times 10^{-4}$ and an unprecedented bandwidth in both atmosphere transparency windows i.e. near $3.5 \mu \mathrm{m}$ and $9 \mu \mathrm{m}$. Following waveguide birefringence optimization an ultra-wideband and polarization insensitive multimode interference coupler was designed. The optimized structure shows a $4.5 \mu \mathrm{m}$ wide bandwidth in transverse electric and transverse magnetic polarization at $9 \mu \mathrm{m}$ wavelength. The developed ultra-wideband polarization insensitive photonic building blocks presented in this work pave the way for further implementation of free space communication systems in the mid infrared spectral region.
\end{abstract}

Keywords: mid-infrared, polarization insensitive, waveguides, MMI, free space communications, silicon-germanium, photonic integrated circuits

\section{INTRODUCTION}

The mid-infrared (mid-IR) spectral region $(\lambda \sim 2-20 \mu \mathrm{m})$ has attracted much attention due to the localization of sharp and strong absorption features of chemical and biological compounds. It has become a region of major interest for a growing number of applications such as astronomy ${ }^{1}$, security and defense ${ }^{2}$, biosensing and medical diagnosis ${ }^{3}$. The use of mid-IR radiation appears to be particularly suitable to realize free-space communications. Indeed, compared to the near infrared (NIR) spectral region, the signals in the mid-IR are more robust against the main background noise sources (city lights, Sun, Moon, Earth). Moreover, with the increase of wavelength from NIR to mid-IR, Rayleigh and Mie scattering are reduced. It is to be mentioned that two transparency windows are localized in Earth's atmosphere absorption spectrum that are very interesting for information transfer: wavelengths localized between 3 and $5 \mu \mathrm{m}$ compose the first window (window 1) while the second window lie within 8-14 $\mu \mathrm{m}$ wavelength range (window 2). Both of these windows can be subdivided in channels, each of them carrying a signal from a directly modulated quantum cascade laser (QCL). Targeting such a wide field of applications numerous photonic platforms have been investigated: chalcogenide glasses ${ }^{4,5}$, 
III-V materials ${ }^{6}$ and $\mathrm{Si}$ and $\mathrm{Si}$ - compatible materials ${ }^{7-18}$. On their basis, key photonic building blocks have been demonstrated: low loss waveguides, spectrometers ${ }^{9}$, cavities ${ }^{4}$, modulators ${ }^{18}$ photodetectors ${ }^{19}$, and light sources ${ }^{20}$. Among Si compatible platforms, the properties of silicon germanium alloys ( $\mathrm{SiGe}$ ) have been investigated. Particularly, the use of germanium (Ge) rich-SiGe alloys on graded buffer combines within the same platform: (i) ultra-wideband operation ${ }^{12}$, (ii) outstanding nonlinear properties ${ }^{13}$, (iii) material tunability ${ }^{12}$. In this work, we implement wideband polarization agnostic photonic components for mid-IR free space communications. Indeed one of the main challenges in free-spacecommunications is the signal processing at the receiver point as the polarization of the incoming light is unknown. For efficient information processing we propose the use of polarization insensitive photonic integrated circuits based on $\mathrm{Ge}$ rich SiGe alloys on graded buffer First, wideband and polarization insensitive Ge-rich SiGe waveguides are designed by judicious optimization of geometrical parameters within the two atmosphere transparency windows. A method is given to optimize the waveguide geometry for a broad wavelength range. Consequently, for these building blocks, the birefringence was kept below $2 \times 10^{-4}$ thus enabling further design of polarization agnostic components and allowing to allocate more than 350 communication channels in each atmosphere transparency window. As a next step, broadband and polarization independent multimode interference coupler (MMI) was designed in the window 2 with and operational $1 \mathrm{~dB}$ wavelength range between 7.5 and $12.65 \mu \mathrm{m}$. The key building blocks in this work pave the way for further development of polarization agnostic photonic integrated circuits for efficient and cost effective mid-IR free-space communications.

*vevakarin@gmail.com

\section{DESIGN OF WIDEBAND AND POLARIZATION AGNOSTIC WAVEGUIDES}

The polarization insensitive waveguides are designed on the basis of Ge-rich SiGe platform as shown on Fig. 1. In the graded layer, the Ge concentration is increased from 0 to 0.79 over a thickness of $11 \mu \mathrm{m}$. Then the graded layer is capped with $2 \mu \mathrm{m}$ thick $\mathrm{Si}_{0.2} \mathrm{Ge}_{0.8}$. The corresponding refractive index evolution follows the increase of Ge concentration thus making a transition from the refractive index of $\mathrm{Si}$ to the one of $\mathrm{Si}_{0.2} \mathrm{Ge}_{0.8}$.

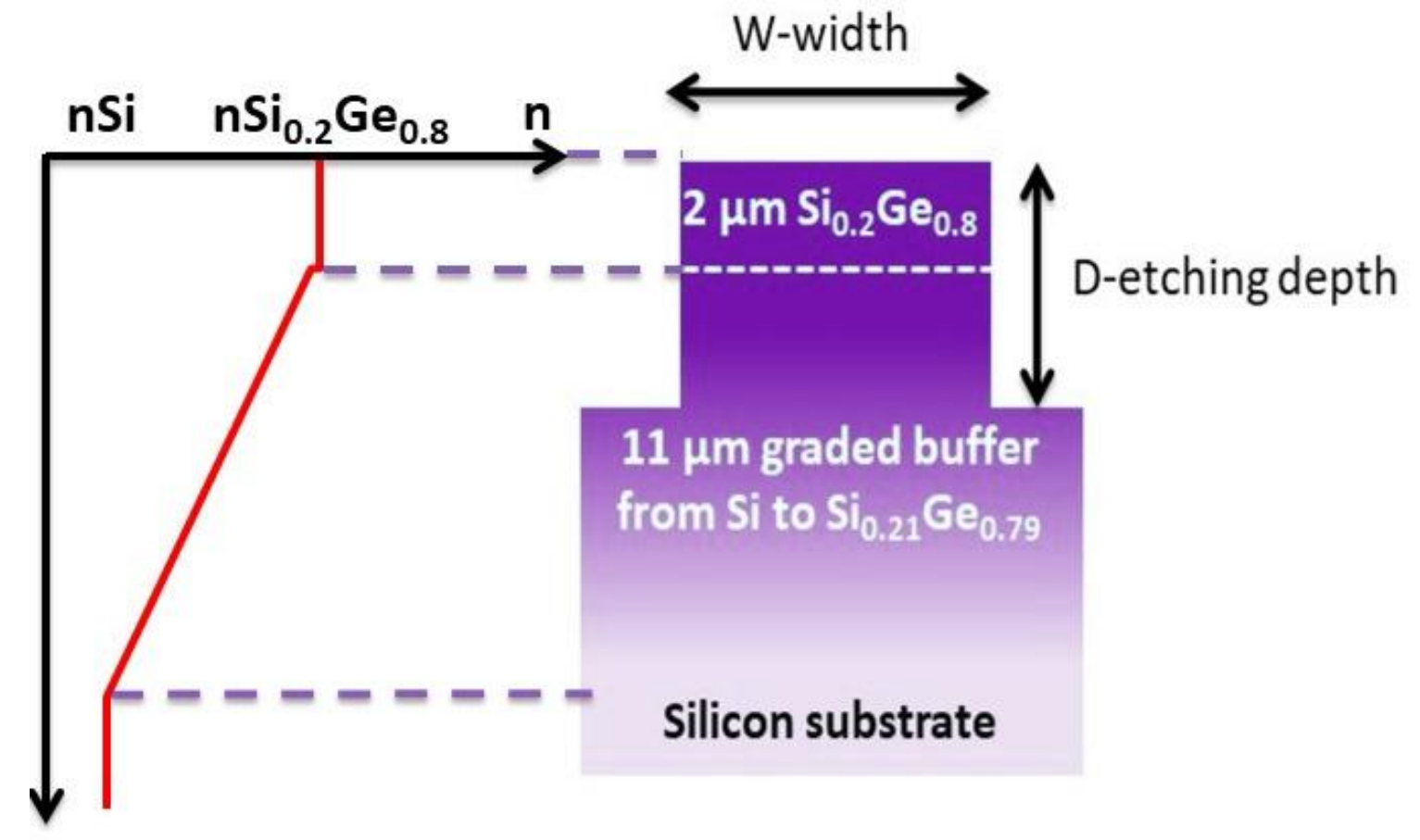

Figure 1. Schematic view of the waveguide cross section with the corresponding epitaxial structure and refractive index evolution in the vertical direction. Depending on the design, the etching depth D can stop inside the $2 \mu \mathrm{m} \mathrm{Si0.2Ge0.8} \mathrm{layer}$ or in the graded buffer. 
From material point of view, the graded buffer assures lattice accommodation between $\mathrm{Si}$ and a Ge-rich SiGe alloy thus reducing optical losses due to epitaxial defects. Interestingly, this layer also isolates the optical mode from Si-rich substrate avoiding losses by multiphonon absorption at wavelengths beyond $8 \mu \mathrm{m}$. Moreover, the presence of the graded layer induces a mode self-adaptation effect which in combination with low material dispersion is responsible for ultrawideband and low loss behavior of these waveguides ${ }^{12}$. On this platform in the past 3 years several key photonic building blocks have been experimentally demonstrated: broadband and low loss waveguides operating in the wavelength range from 5 to $8.5 \mu \mathrm{m}^{12}$, broadband Mach Zehnder interferometers ${ }^{14}$ and spectrometers ${ }^{15}$ and more recently Fabry Perot cavities ${ }^{16}$ and racetrack resonators ${ }^{17}$. However, in all these previous works polarization insensitivity of photonic components has not been investigated.

In the mid-IR, refractive index dispersion of the group IV materials such as $\mathrm{Si}$, Ge or their alloys is very low ${ }^{21}$. Consequently, as mode dispersion will be dominant, to optimize Ge-rich SiGe waveguides for polarization insensitive operation we choose to optimize their geometrical parameters: width $\mathrm{W}$ and etching depth $\mathrm{D}$ (see Fig. 1). Here we propose a design method to obtain wideband polarization insensitive behavior. The proposed method comprises the following steps: (i) within the selected atmosphere transparency window, the birefringence i.e. the difference between the effective indexes of the fundamental transverse electric mode (neff $\mathrm{TE}_{\mathrm{TE}}$ ) and the transverse magnetic mode (neff $\mathrm{TM}_{\mathrm{TM}}$ ) is plotted as function of $\mathrm{W}$ and $\mathrm{D}$, (ii) from birefringence maps, the beating length $\mathrm{L}_{\pi_{\_} \text {guide }}$ is calculated (Eq. (1)) as a function of $\mathrm{W}$ and $\mathrm{D}$. Indeed a polarization insensitive geometry should lead to a maximal $\mathrm{L}_{\pi_{\_} \text {guide }}$, (iii) the geometrical mean value $\mathrm{L}_{\text {geom }}$ is calculated according to Eq. (2) over the selected wavelengths and the corresponding map is plotted with respect to waveguide geometrical parameters. A waveguide defined by the couple $(\mathrm{W}, \mathrm{D})$ that will maximize $\mathrm{L}_{\mathrm{geom}}$ will be polarization insensitive over the broadest wavelength range and should be selected. If $\mathrm{L}_{\text {geom }}$ is maximized for different waveguide geometries, the couple (W, D) leading to a lower number of modes in the waveguide should be chosen.

$$
\begin{gathered}
\mathrm{L}_{\pi_{- \text {guide }}}=\frac{\lambda}{2\left|n e f f_{T E}-n e f f_{T M}\right|} \\
\mathrm{L}_{\text {geom }}=\left(\prod_{j=1}^{M} L_{\pi_{j}}\right)^{1 / M}
\end{gathered}
$$

This method is applied in both atmosphere transparency windows. We illustrate in details the waveguide cross section optimization in the mid-IR window1. As an example, a birefringence map is plotted on Figs 2(a) with the zero birefringence line at the wavelength $4 \mu \mathrm{m}$. Then, as can be observed from the $\mathrm{L}_{\text {geom }}$ map (calculated for 10 different wavelengths), two different regions maximize $\mathrm{L}_{\text {geom }}$, Fig. 2(b). The first region, in the green dashed rectangle, composed of waveguide geometries with etching depths ranging from 2.5 to $5 \mu \mathrm{m}$ and with widths between 4 and $5 \mu \mathrm{m}$ is not taken under consideration as these waveguides with such dimensions would exhibit highly multimode behavior i.e. more than 2 modes in each polarization. The second is the bottom zone in the dashed blue rectangle. In this zone we choose the waveguide with the following dimensions: $\mathrm{W}=3.4 \mu \mathrm{m}$ and $\mathrm{D}=1.9 \mu \mathrm{m}$. Optical mode calculation show similar confinement for transverse electric (TE) and transverse magnetic polarizations (TM), Fig. 3(a). We plot the birefringence of this waveguide within the mid-IR window 1, Fig. 3(b). The proposed geometry guaranties a birefringence below the value of $2 \times 10^{-4}$ between the wavelengths of 3 and $4.8 \mu \mathrm{m}$ i.e. covering almost entirely the window 1 . Such a low birefringence implies that at the wavelength of $4 \mu \mathrm{m}$ TE and TM polarized modes will be $\pi$-shifted only after propagation over a distance of $1.2 \mathrm{~cm}$. It is to be mentioned that this propagation distance is comparable to the dimensions of silicon photonic chips. Similarly, wideband polarization insensitive operation has been obtained in the window 2 for the waveguide with $\mathrm{W}=5.4 \mu \mathrm{m}$ and $\mathrm{D}=3.1 \mu \mathrm{m}$ as can be observed from mode profiles (Fig. 3(c)) and spectral birefringence evolution (Fig. 3(d)). The birefringence is kept below $2 \times 10^{-4}$ across the wavelengths of 8.22 and $10.36 \mu \mathrm{m}$ with the corresponding $\mathrm{L}_{\pi_{\text {_guide }}}$ higher than $2 \mathrm{~cm}$. Thus, a major part of mid-IR windows 1 and 2 can successfully be covered only with 2 waveguide geometries. It is interesting to realize what this represents in terms of number of communication channels. For instance, if we take a channel of $5 \mathrm{~nm}$ that can contain one modulated QCL laser line, the Ge-rich SiGe waveguide optimized for window 1 can support 360 channels, whereas in the window 2 with the dedicated polarization insensitive SiGe waveguide geometry we can cover 428 channels. 

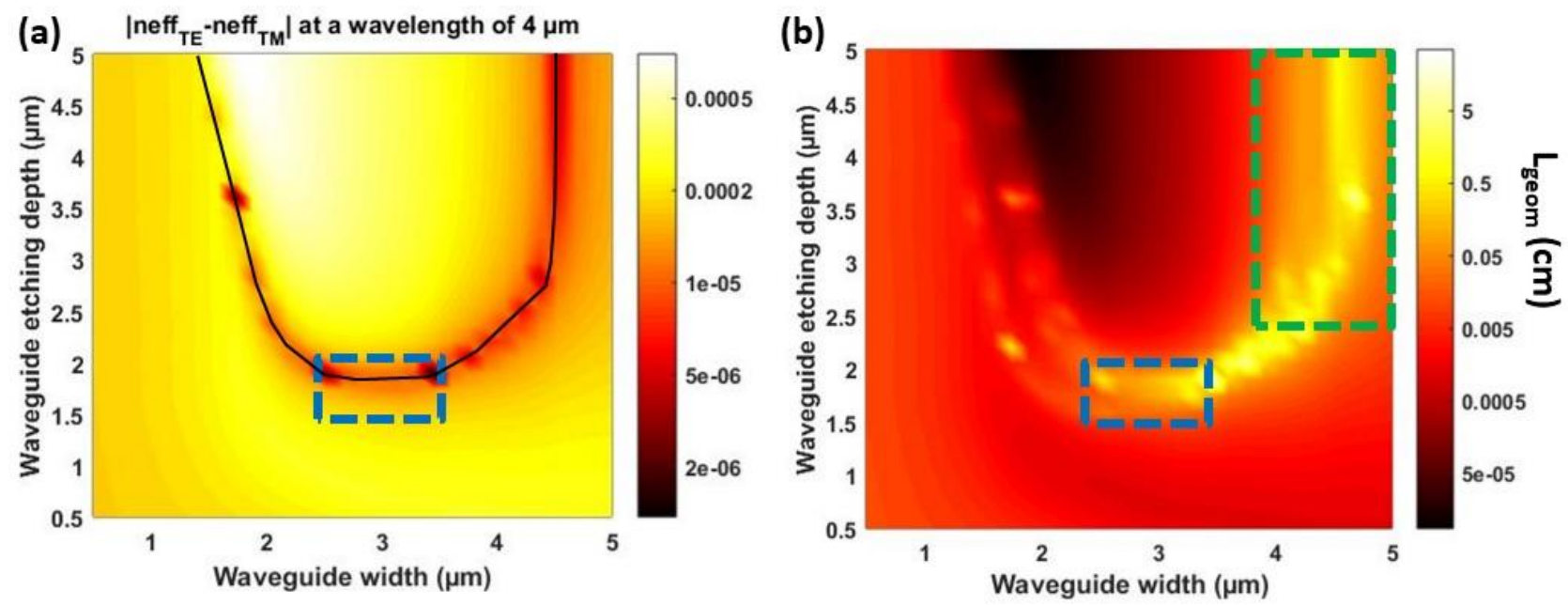

Figure 2. (a) Birefringence cartography as function of waveguide dimensions for the wavelengths of $4 \mu \mathrm{m}$. The black line corresponds to zero birefringence or neff $\mathrm{TE}_{\mathrm{TE}}=$ neff $_{\mathrm{TM}}$. (b) $\mathrm{L}_{\mathrm{geom}}$ as function of waveguide dimensions. Blue dashed rectangle corresponds to wavelength invariant low birefringence zone.

(a)

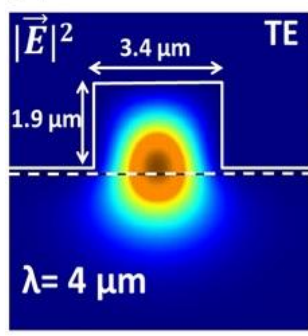

(c)

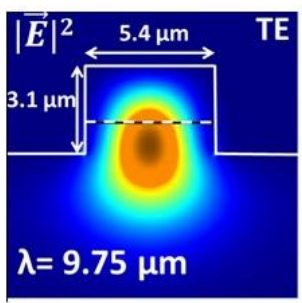

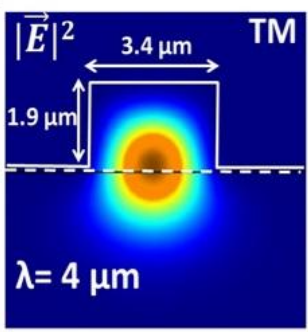

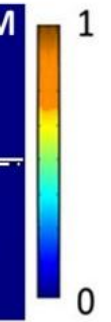

(b)

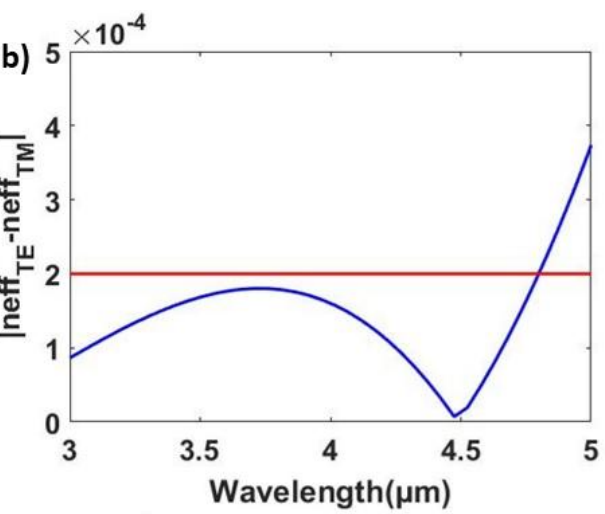

(d)
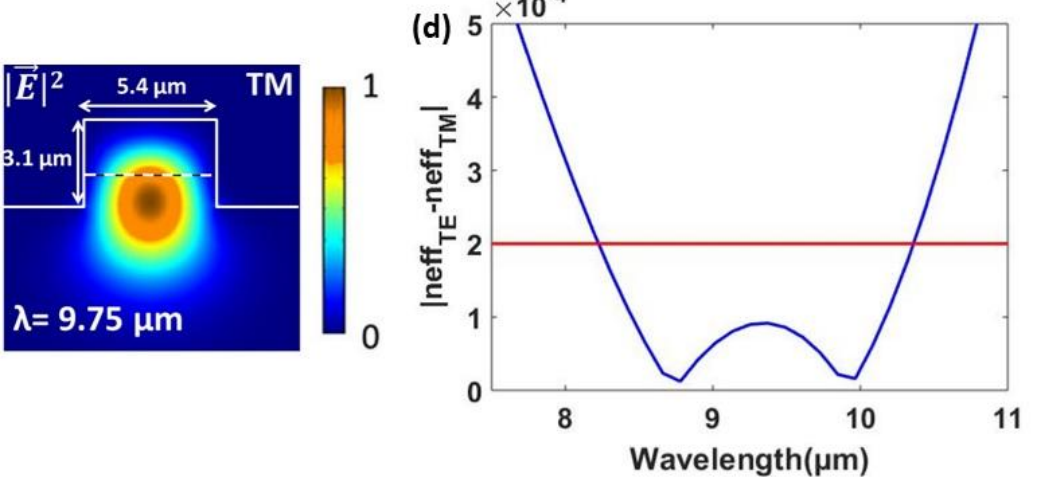

Figure 3. (a) Optimized waveguide cross section in the mid-IR window 1 with the corresponding field intensity profile for both polarizations and (b) associated birefringence evolution as function of the wavelength. (c). Optimized waveguide cross section in the mid-IR window 2 with the corresponding field intensity profile for both polarizations and (d) associated birefringence evolution as function of the wavelength. 


\section{BROADBAND AND POLARIZATION INSENSITIVE MMI}

As a next step, following the optimization of the waveguides, a wideband polarization insensitive MMI was designed in the window 2 of the atmosphere. First, the MMI width was chosen according to modal analysis. At a given light polarization (TE or TM), the optimum MMI length, $\mathrm{L}_{\mathrm{opt}}$ is related to the beating length $\mathrm{L}_{\pi}$ (see Eq. (3)) between the two first order modes as following defined by Eq.(4).

$$
\begin{gathered}
\mathrm{L}_{\pi}=\frac{\lambda}{2\left|n e f f_{\text {model }}-n e f f_{\text {mode2 }}\right|} \\
\mathrm{L}_{\mathrm{opt}}=\frac{3}{8} L_{\pi}
\end{gathered}
$$

It can be seen, that to obtain a polarization insensitive MMI over a broadband spectral range we need to minimize the difference between the $L_{\pi}$ in TE and TM polarizations over the full operational wavelength range. To ease further integration, we choose to fix the etching depth of the MMI to $3.1 \mu \mathrm{m}$ i.e. identic to the one of polarization insensitive waveguide in the window 2. The width of MMI is varied between 20 and $30 \mu \mathrm{m}, 20 \mu \mathrm{m}$ being the smallest width value that guarantees the presence of at least $3 \mathrm{TE}$ modes in the structure at the wavelength of $13 \mu \mathrm{m}$. Then, for both polarizations the effective indexes of the two first modes (Fig. 4(a) and (b)) are calculated as well as the corresponding $\mathrm{L}_{\pi}$ value. For each MMI width value this calculation is performed for all the wavelengths between 7.5 and $13 \mu \mathrm{m}$ and the difference in $\mathrm{L}_{\pi}$ between both polarizations is plotted, as shown on Fig. 4(c). As can be seen, the difference between $\mathrm{L}_{\pi}$ is increasing with the MMI width and with wavelength. Consequently, a width of $20 \mu \mathrm{m}$ was chosen for the MMI as the corresponding $\mathrm{L}_{\pi}$ difference is minimized and has almost flat spectral behavior.
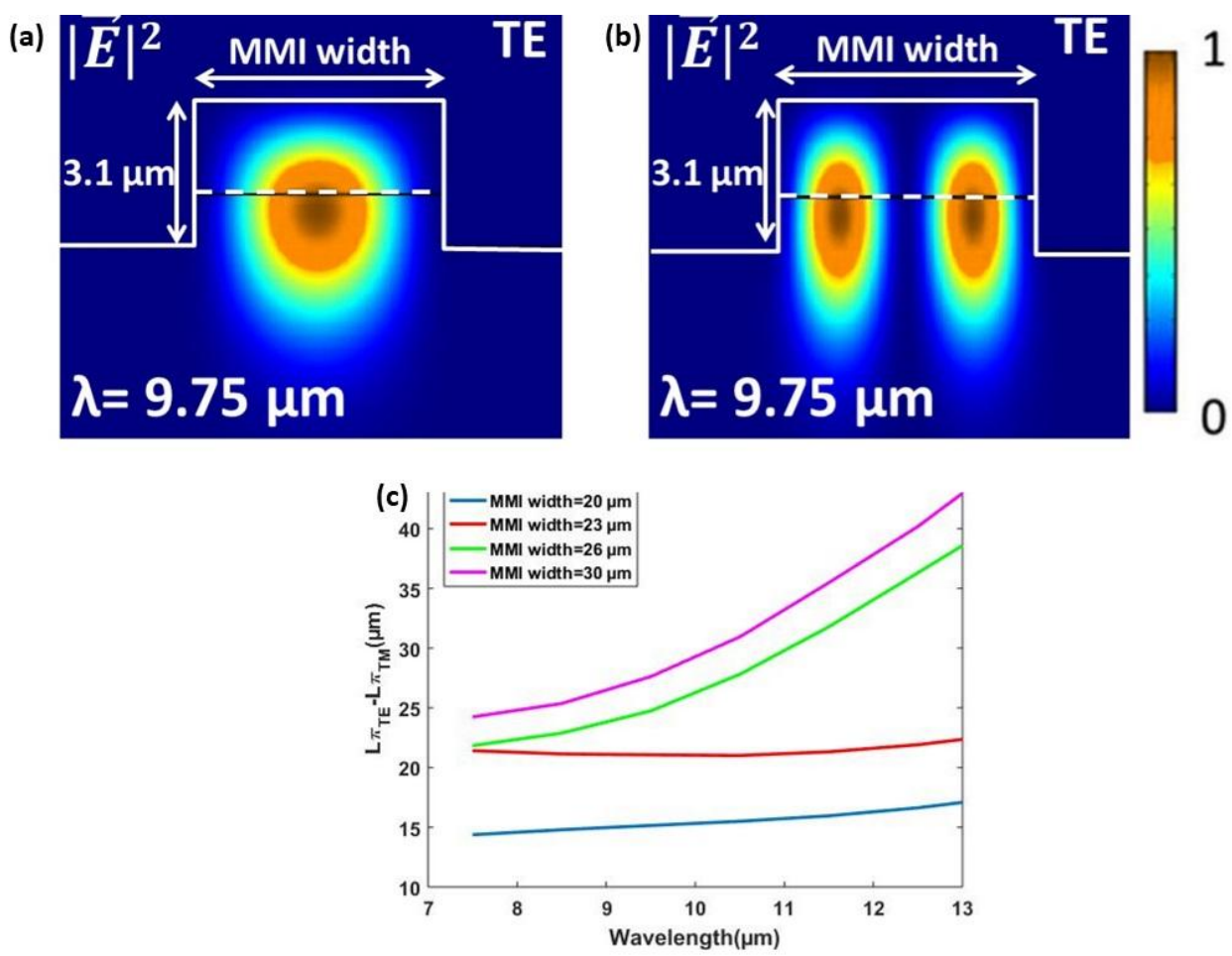

Figure 4. MMI cross-section view with field intensity profiles of (a) first and (b) second order modes at the wavelength of $9.75 \mu \mathrm{m}$. (c) MMI beating length difference between TE and TM polarization evolution as function of operational wavelength and MMI width. 
Knowing the optimal MMI width further optimization of the structure was performed using propagation simulations for the wavelength range from $7.5 \mu \mathrm{m}$ to $13 \mu \mathrm{m}$. As a result, the structure depicted on Fig. 5(a) was obtained. It consists in a $84 \mu \mathrm{m}$-long MMI with $80 \mu \mathrm{m}$ input/output couplers. The field intensity profiles are similar for TE (Fig. 5(b)) and TM (Fig. 5(c)) mode. Moreover, the structure has a remarkable spectral behavior: the $-1 \mathrm{~dB}$ bandwidth for TE polarization extends from the wavelength of $7.5 \mu \mathrm{m}$ up to $12.65 \mu \mathrm{m}$ (Fig. $5(\mathrm{~d}))$ and for TM polarization from $7.5 \mu \mathrm{m}$ up to $13 \mu \mathrm{m}$. Consequently the designed wideband polarization insensitive MMI is covering almost entirely the mid-IR transparency window 2.

(a)

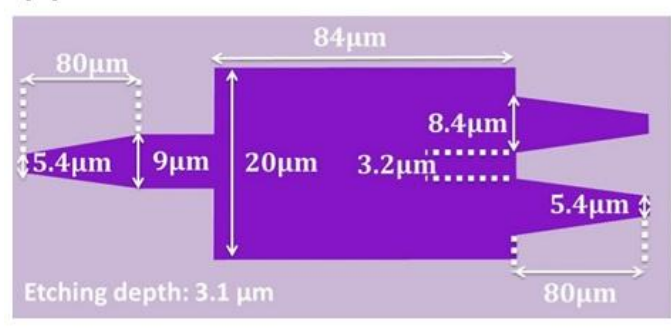

(c)

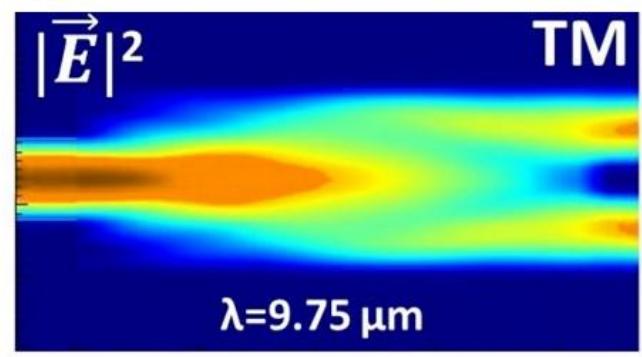

(b)
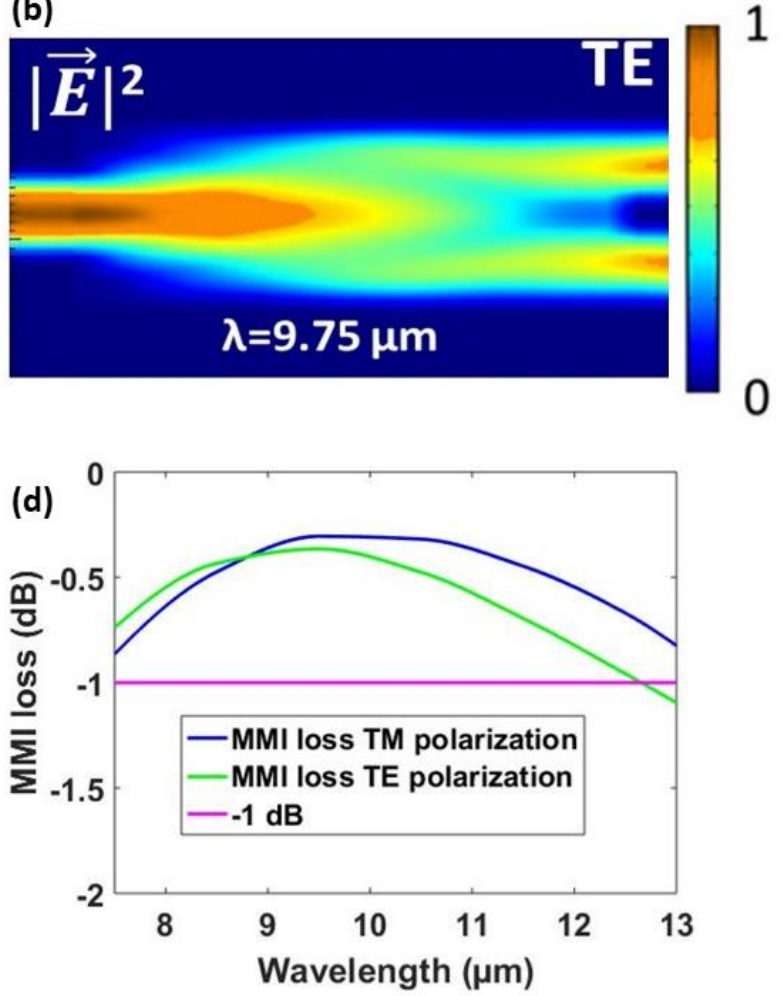

Figure 5. (a) Schematic view of the optimized polarization insensitive MMI structure. (b) Field intensity profile in the structure, TE polarization. (c) Field intensity profile in the structure, TM polarization. (d) Loss in the MMI structure in TE (green) and TM (blue) polarization.

\section{CONCLUSION}

In summary, we designed wideband polarization insensitive waveguides based on Ge-rich SiGe platform in both atmosphere transparency windows. The optimized waveguides exhibit a birefringence below $2 \times 10^{-4}$ on their full operation wavelength range thus enabling the allocation of more than 350 communication channels in each transparency window. To go further a wideband polarization insensitive MMI coupler has been designed with a $-1 \mathrm{~dB}$ operational bandwidth exceeding $5 \mu \mathrm{m}$ for both polarizations. This key building block can be used afterwards to build polarization agnostic integrated multiplexers and demultiplexers, Fourier-Transform spectrometers, optical switches. The polarization insensitive components designed in this work are the first step for future implementation of efficient free-space communications in the mid-IR spectral region. 


\section{ACKNOWLEDGMENT}

This project has received funding from the European Research Council (ERC) under the European Union's Horizon 2020 research and innovation program (grant agreement $\mathrm{N}^{\circ} 639107-$ INsPIRE).

\section{REFERENCES}

[1] Labadie, L. and Wallner, O., "Mid-infrared guided optics: a perspective for astronomical instruments, ” Opt. Express 17, 1947(2009).

[2] Chang, Y. C., Wägli, P., Paeder, V., Homsy, A., Hvozdara, L., van der Wal, P., Francesco, J. Di., de Rooij, N.F., and Herzig, H. P., Lab. Chip, 12, 3020 (2012)

[3] Yu, C., Ganjoo, A., Jain, H., Pantano, C. G., Irudayaraj, J., "Mid-IR biosensor: detection and fingerprinting of pathogens on gold island functionalized chalcogenide films," Anal. Chem. 78, 2500 (2006).

[4] Lin, H., Li, L., Zou, Y., Danto, S., Musgraves, J. D., Richardson, K., Kozacik, S., Murakowski, M., Prather, D., Lin, P. T., Singh, V., Agarwal, A., Kimerling, L. C., and Hu, J., "Demonstration of high-Q mid-infrared chalcogenide glass-on-silicon resonators," Opt. Lett. 38, 1470-1472 (2013).

[5] Gutierrez-Arroyo, A., Baudet, E., Bodiou, L., Lemaitre, J., Hardy, I., Faijan, F., Bureau, B., Nazabal, V., and Charrier, J., "Optical characterization at $7.7 \mu \mathrm{m}$ of an integrated platform based on chalcogenide waveguides for sensing applications in the mid-infrared," Opt. Express 24, 23109-23117 (2016).

[6] Roux, S., Cerutti, L., Tournié, E., Gérard, B., Patriarche, G., Grisard, A. and Lallier, E., "Low-loss orientationpatterned GaSb waveguides for mid-infrared parametric conversion," Opt. Mater. Express 7, 3011-3016 (2017).

[7] Penadés, J. S., Sánchez-Postigo, A., Nedeljkovic, M., Ortega-Moñux, A., Wangüiemert-Pérez, J. G., Xu, Y., Halir, R., Qu, Z., Khokhar, A. Z., Osman, A., Cao, W., Littlejohns, C. G., Cheben, P, Molina-Fernández, I., and Mashanovich, G. Z., "Suspended silicon waveguides for long-wave infrared wavelengths," Opt. Express 26, 528-531 (2017).

[8] Nedeljkovic, M., Penades, J. S., Mittal, V., Senthil Murugan, G., Khokhar, A. Z., Littlejohns, C., Carpenter, L. G., Gawith, C. B. E., Wilkinson, J. S., and Mashanovich, G. Z., "Germanium-on-silicon waveguides operating at mid-infrared wavelengths up to $8.5 \mu \mathrm{m}$," Opt. Express 25, 27431-27441 (2017).

[9] Nedeljkovic, M.; Velasco, A.V.; Khokhar, A.Z.; Delâge, A.; Cheben, P.; Mashanovich, G.Z. Midinfraredsilicon-on-insulator Fourier-transform spectrometer chip. IEEE Photonics Technol. Lett. 2016, 28, 528531.

[10] Malik, A., Muneeb, M., Pathak, S., Shimura, Y., Van Campenhout, J., Loo, R., and Roelkens, G., "Germaniumon-silicon mid-infrared arrayed waveguide grating multiplexers," IEEE Photonics Technol. Lett. 25(18), 18051808 (2013).

[11] Sinobad, M., Monat, C., Luther-Davies, B., Ma, P., Madden, S., Moss, D. J., Mitchell, A., Allioux, D., Orobtchouk, R., Boutami, S., Hartmann, J.-M., Fedeli, J.-M., and Grillet, C., "Mid-infrared octave spanning supercontinuum generation to $8.5 \mu \mathrm{m}$ in silicon-germanium waveguides," Optica 5, 360 (2018).

[12] Ramírez, J. M., Liu, Q., Vakarin, V., Frigerio, J., Ballabio, A., Le Roux, X., Bouville, D., Vivien, L., Isella, G., and Marris-Morini, "Graded SiGe waveguides with broadband low-loss propagation in the mid infrared," Opt. Express 26, 870 (2018).

[13] Serna, S., Vakarin, V., Ramírez, J. M., Frigerio, J., Ballabio, A., Le Roux, X., Vivien, L., Isella, G., Cassan, E., Dubreuil, N. , and Marris-Morini, D. ,"Nonlinear Properties of Ge-rich Si1-xGex Materials with Different Ge Concentrations," Sci. Rep. 7, 1-11 (2017).

[14] Vakarin, V., Ramírez, J. M., Frigerio, J., Ballabio, A., Le Roux, X., Liu, Q., Bouville, D., Vivien, L., Isella, G., and Marris-Morini, D., "Ultra-wideband Ge-rich silicon germanium integrated Mach-Zehnder interferometer for mid-infrared spectroscopy," Opt. Lett. 42, 3482 (2017).

[15]Liu, Q., Ramírez, J.M., Vakarin, V., Le Roux, X., Alonso-Ramos, C., Frigerio, J., Ballabio, A., Talamas Simola, E., Bouville, D., Vivien, L., Isella, G., Marris-Morini, D., Integrated broadband dual-polarization Gerich SiGe mid-infrared Fourier-Transform spectrometer,Opt. Lett. 43, 5021 (2018).

[16]Liu, Q., Ramírez, J. M., Vakarin, V., Le Roux, X., Frigerio, J., Ballabio, A., Talamas Simola, E., AlonsoRamos, C., Benedikovic, D., Bouville, D., Vivien, L., Isella, G., and Marris-Morini, D., "On-chip Bragg grating waveguides and Fabry-Perot resonators for long-wave infrared operation up to $8.4 \mu \mathrm{m}$," Opt. Express 26, 34366-34372 (2018). 
[17] Ramírez, J. M., Liu, Q., Vakarin, V., Le Roux, X., Frigerio, J., Ballabio, A., Alonso-Ramos, C., Talamas, E., Vivien, L., Isella, G., and Marris-Morini, D., "Broadband integrated racetrack ring resonators for long-wave infrared photonics ", accepted in Opt. Lett. 2018.

[18] Cao, W., Hagan, D., Thomson, D. J., Nedeljkovic, M., Littlejohns, C. G., Knights, A., Alam, S.-U., Wang, J., Gardes, F., Zhang, W., Liu, S., Li, K., Rouifed, M. S., Xin, G., Wang, W., Wang, H., Reed, G. T. and Mashanovich, G. Z., "High-speed silicon modulators for the $2 \mu \mathrm{m}$ wavelength band," Optica 5, 1055-1062 (2018).

[19] Yakimov, A. I., Kirienko, V. V., Bloshkin, A. A., Armbrister, V. A., Dvurechenskii, A. V., and Hartmann, J.M., "Photovoltaic Ge/SiGe quantum dot mid-infrared photodetector enhanced by surface plasmons," Opt. Express 25, 25602-25611 (2017)

[20] Nguyen-Van, H.; Baranov, A.N.; Loghmari, Z.; Cerutti, L.; Rodriguez, J.B.; Tournet, J.; Narcy, G.; Boissier, G.; Patriarche, G.; Bahriz, M.; et al. "Quantum cascade lasers grown on silicon", Sci. Rep. 2018, 8, 7206.

[21] Soref, R., "Mid-infrared photonics in silicon and germanium," Nature Photonics, 4, 495 (2010). 